the profession, is altogether unworthy of them, while some of their sentiments are at variance with the resolutions which have already emanated from their Reform Committee, and to which the Fellows are understood to have yielded their assent. Such vacillating proceedings afford just grounds to the profession to distrust their sincerity in carrying out the measures to which they stand pledged. The College of Physicians know full well, that whatever may be the reasons for or against the union of all classes of the Medical Profession into one body for corporate privileges, the question is in itself perfectly distinct from that of the existence of grades; the endeavour, therefore, to mix up the two questions in their petition, and the bringing of this question of grades prominently forward as an objection to reform measures, in which it is not necessarily concerned, is uncandid, and can be considered only in the light of an attempt to take an unfair advantage of the ignorance of those who, although they may have to legislate on the subject, are necessarily but little qualified to understand its merits. The Fellows of the College have an undoubted right to form their own opinion. From the position in which they are placed, that opinion may be naturally expected to be biassed and partial, and we are not disposed to blame them for this. It is in the natural course of events, and we expect not that every man should be able to view correctly things as they are, through the same medium. But we do expect candour and upright dealing from a body of gentlemen, who especially profess high moral and intellectual attainments, whose acts of exclusion have, indeed, been attempted to be justified on the presumed possession, in an eminent degree, of these very attainments by the persons admitted to a participation of their privileges. We feel, therefore, the more disappointed at the tone of their petition, and our confidence shaken in the promises made by them of the adoption of measures which, if not unexceptionable, are nevertheless, in the main, such as might be received by the profession without degradation. A more recent petition, which we inserted in our last number, we regret to say, holds out but little inducement for a renewal of confidence, and we are induced to defer the expression of our opinion in more decided terms, only in the expectation that the bill of the Corporations will shortly be before us.

\section{HARVEIAN SOCIETY.}

ON THE TREATMENT OF STAMMER BY SURGICAL OPERATION.

BY P. BENNET LUCAB, ESQ

Burgeon to the Metropolitan Free Hospital, Lecturex on Surger J at the Hunterian School of Medicine, \&c.

To understand the nature of the defect to which the popular terms stammer or stutter have been applied, it is evident that a most serious consideration of the structure, connexions, and uses of the several organs directly or remotely concerned in the pronunciation of words is necessary. At the present moment this investigation is particularly called for, on account of surgery, in its operative department, essaying for the first time to cure or alleviate a distressing infirmity, which has in too many instances hitherto baffled the bestdirected energies of the other departments of medical science; and, as a necessary result, has left uncultivated an extensive field, in which, as is ever the case, the empiric has not been slow to exhibit himself as an apparently scientific and assiduous labourer.

In approaching a subject of this kind I almost pause at its very threshold, in consequence of the complexity of the system of organs which are engaged in the pronunciation of words, a defect in any one of which it is rational to suppose must be accompanied with some defect in speech; and I more especially do so, when I reflect that some eminent members of our profession have already directed their attention to the nature of the defect under consideration; but who, having based a practice upon views confined to a portion only of the complicated apparatus for speech, have necessarily promulgated opinions which have been as imperfect as the practice which they have recommended has been found wanting.

Another source of difficulty in properly investigating the subject of stammer presents itself in the novelty which obtains to the new endeavour to cure or relieve it by surgical operation; and which already promises to raise as large a host of unreflecting tongue cutters, and tonsil excisors, as the interesting operation which immediately preceded it did squint cutters. The history of the new operation for strabismus is pregnant with proofs of the truth of these remarks, and offers a salutary lesson, of an otherwise useful operation being likely to get into disrepute, from a desire of display in its performance on the one hand, or an anxiety to exceed in the amount of cases on the other. It is a striking coincidence that two organs so distinctly opposite in their functions, as the eye and the tongue, should have lately been the subjects of operation for the relief of vices not directly connected with the essential function of either. In one, the muscles have been divided to remove rather a personal deformity than to improve vision; in the other the muscles have been divided to remove a defect in utterance, and not to interfere with the sense of taste. Whilst the most gratifying success has attended, in almost every case of strabismus, the judicious division of the muscle or muscles at fault, it is very doubtful if the division of the lingual muscles will accomplish effects so decided; and it is certain that such an operation cannot have so extensive an application to the muscles of the tongue as to those of the eye. The muscles which move the human eyes are so perfectly distinct from each other, that even their dimensions as to length, breadth, and thickness have been ascertained;" bence the certainty with which the surgeon can remove the eye-balls from the influence of them by operation. But the muscles which move the tongue, although the majority

-Vide "A Treatise on Strabismus, by P. Bennett Lucas," pp. 19-21. 
of them are distinct enough at their origins, and, for part of their course, become at length so intermingled with each other, and with the other tissues of the tongue, that they defy the labour of the anatomist to display their individual continuity; and even could dissection satisfy curiosity on this head, it is even doubtful if any practical utility in the treatment of stammer would be the result.

It would obviously be impossible, in a short paper of this kind, to enter into an investigation of the organs concerned in speech, much less to give a detail of the different opinions which have been advanced, from time to time, on the nature and seat of stammer; and even had I prepared such, I should only have recapitulated a description of organs with which, doubtless, all the members of this society are familiar, and have collected a history of opinions, equally well known, from sources accessible to all.

I shall, therefore, confine my observations to an account of a few operations which $I$ have lately performed on some of the muscles of the tongue with a view to the relief or cure of stammer; and to other operations which have been performed with similar objects. The first intimation I had of the cure of stutter by operation was from a newspaper, in which it was stated that Professor Dieffenbach had divided some of the muscles of the tongue with the most brilliant success. On February $23 d$ an opportunity was afforded me, in the case of Patrick Heron, of putting into practice, by operation, some views which the newspaper account alluded to led me to adopt for the cure of stammer. This operation had for its object the division, and partly removal, of those muscles which oppose the free elevation of the tip of the tongue to the superior alveolar arches.

Besides six cases which have already been laid before the profession in the pages of the Provincial Medical and Surgical Journal, I have operated precisely in the same manner upon twelve others; and I should be wanting in respect to myself, and in candour to the members of my profession, did I not explicitly state that four of the latter were not in any way benefited by the operation. Of the remaining eight, three were cured and five considerably relieved.

The following case, taken from my note-book, upon which I operated this week, is a good example of the beneficial effects of the proceeding : -Mr. Mosely, aged 22, has stammered since he can recollect. This case is an excellent one to try the operation; his palate is narrow and very deep; when his mouth is open, he cannot elevate his tongue more than half way to the superior alveoli; his frænum linguæ is very tense when he attempts this movement. The only words he stammers at are those which require the tip of the tongue to be applied to the upper alveoli. His engagements make him anxious to pronounce distinctly the price of articles of merchandize; and he tests the intensity of his infirmity by the expressions, nine and nine-pence, nine and ten-pence, ten and ninepence, \&c.

Thinking that the frænum linguæ might have been the impediment to his utterance, I divided it freely, but with no good effect; I next divided and excised portions of the genio-glossi muscles, and his ability to pronounce correctly his wishedfor expressions became at once apparent to those present, as well as to the patient himself.
Four days after the operation I saw this patient. His ability to pronounce words containing the letters $t, l, d, n, \& c$., remains without any impediment. He expresses himself as perfectly satisfied with the results of the operation.

Three weeks after the operation on Patrick Heron, his stammer remains greatly relieved; he occasionally stammers at his old words, but only for two or three seconds. This man was a patient at the hospital for chronic enlargement of his right testicle four months ago, and he found the greatest difficulty in expressing himself; hesitating at times so long that I had repeatedly to send him away without his being able to make himself understood, and speak to him when I had seen the other patients.

In addition to my own cases, operations performed by Amussat, Velpeau, and Boyer, have been conducted in the same manner, and with similar results. Roux, also, is so satisfied of the soundness of such an operation, when applied to proper cases, that he announced his intention of performing it at the Hôtel-Dieu, but as yet no account has been afforded of the results of his practice.

One recommendation which this operation offers is its extreme simplicity; another, the obvious views on which it is based; and, above all, that the life of the patient is not hazarded by its performance. The operation which I perform is as follows:The patient being seated before a strong light, and his head resting against the breast of an assistant, I make him open his mouth fully, and elevate his tongue, which movement puts the frænum linguæ upon the stretch. In most instances the patient can keep his tongue for a sufficient time in this position to enable the operator to accomplish the object intended; but if he should not be able to do so-if the tongue be unsteady, as it sometimes is, - the assistant who supports the head can readily keep the organ elevated and steady with his fingers, having first covered them with a napkin. I next seize the frænum with a common dissecting forceps, held in my left hand, and with a pair of sharp-pointed scissors I divide this membrane across, and also the mucous membrane laterally and vertically. After this is accomplished, the borders of the genio-hyoglossi muscles, often without any more dissecting, are brought into view; but in other instances it has occurred that a fascia and cellular tissue intervened between them and the frænum, so as to render this part of the operation more difficult, not only on account of the other parts which require to be divided, but also on account of the depth of the muscles from the surface. At this part of the operation there is often hæmorrhage from some of the sub-lingual veins being divided, but never more than to the amount of a small spoonful, and the flow of saliva also from the Whartonian ducts is considerable. At other times there have not been more than a few drops of blood. If the hæmorrhage should obscure the further steps of the operation, the patient should wash his mouth with cold water two or three times, when it. soon ceases. When the free borders of the muscles are brought into view, I seize them with the same forceps that was used for grasping the frænum, and I cut a triangular portion out of each with the sharp-pointed scissors. The re ason I prefer the latter to be sharp-pointed is, that I am enabled to see better what I am about. The 
quantity of muscle I remove depends upon circumstances. After having removed the quantity apparently necessary for the free and perfect elevation of the tongue, I place the point of my forefinger in the wound, and if any parts become tense when the tongue is being raised, I free the organ from their influence. The proximity of the ranine arteries, the large sub-lingual veins, and considerable branches of the sub-lingual and gustatory nerves, makes it necessary to observe caution in the excision of the muscles. The only evidence of injury done to any of these parts in the operations I have performed was a tingling pain shooting from the seat of the operation to the base of one, and sometimes to those of both. This sensation, however, subsided in a few minutes. In a few days the wound is completely healed, and in general no trace of the frænum linguæ is left.

It was not until the operation of dividing and excising the genio-hyoglossi muscles had been performed in this country, and I believe also in Paris, that the particulars of the newspaper account of the cure of stammering by Professor Dieffenbach was made public. And a translation of Professor Dieffenbach's proceedings, the revision of which was submitted to the learned professor himself, has been since made by Mr. Joseph Travers, and published by Mr. Highley; and another translation of the memoir on the subject, sent to the Institute of France by Professor Dieffenbach, has also appeared in the Provincial Medical and Surgical Journal. The object of Professor Dieffenbach's operation he states to be the interruption of the stream of nervous influence, either forwards or backwards, in one of the muscular structures implicated in stutter; and to effect this he determined to perform a division of the root of the tongue in various ways, and under several modifications, always, however, adhering to the general principle, of all but total division, as from the interruption thus given to the morbid nervous influence he could alone hope for a favourable result.

Professor Dieffenbach states that he has given trial to three methods of operating, all of which have for their object total division of the root of tongue. These three operations, according to the translation of Mr. Travers, revised by Dieffenbach, are-

1. The transverse horizontal division of the root of the tongue.

2. The sub-cutaneous transverse division, in which the mucous covering of the tongue is left inviolate.

3. The horizontal division, with excision of a wedge-shaped portion.

These three operations evidently accomplish the object for which they were intended; and notwithstanding "the simple division of the root of the tongue" failed, "the sub-cutaneous division of the root of the tongue" only " ameliorated" a high degree of stuttering, and " was not fully satisfactory ;" but "the horizontal division, with excision of a wedge-shapen portion," was attended with such "brilliant success" that Professor Dieffenbach " had the honour to present him to his excellency the Baron Humboldt, who testified the liveliest interest in the happy re-establishment of the boy."

I apprehend that few surgeons who read the history of this latter case will not subscribe to the reflection of Professor Dieffenbach, viz. "Here some shortening of the tongue must necessarily ensue; and, forasmuch as the base of the wedgeshaped slice is made from the dorsum of the tongue, elevution of the tip must take place. This method, then, mechanically assists that organ, the position insisted upon by those teachers who have been most successful in ameliorating this defect."

The cases which Professor Dieffenbach relates as having operated upon were certainly of an extreme and painful nature, and should cases present themselves in which the individuals were burdens to themselves and to society, I should not hesitate to perform the operation approved of by Professor Dieffenbach, upon the authority of that talented and ingenious individual. But I confess that it would require most serious reflection on my own part, and the judgment of others, whose contributions to surgery as a science, or whose tried public characters as practitioners, rendered them worthy of confidence, before deciding upon the propriety of adopting an operation-not so severe from the nature of its execution, as likely to be followed by ill consequences to the patient.

I have only in one instance removed the tonsils and a portion of the uvula in a stammerer, and in another the entire uvula, but without the least good effect. I regretted afterwards having performed these operations, not from any ill effect which followed, but being satisfied before doing so that this was not the quarter to look for the cause of theaffection; didenlarged tonsils or relaxed uvula, or the three, give rise to stutter, this defect would be very common indeed, for not only do we meet with in our daily practice innumerable patients with enlarged tonsils or uvulæ, telling us without the least impediment of the nature of their affection; but in all the cases where these parts suffer from acute inflammation, we should naturally expect stammer to be a most prominent symptom.

I have purposely omitted mentioning until now the opinion of Dr. Arnot and many others, that the immediate cause of stammering is a spasmodic affection of the glottis, by which an arrest of the passage of the air necessary to pronunciation takes place. Investigations which I have lately made on patients incline me to think that too much weight has been attached to this opinion. I have first examined persons who did not stammer, and found they could pronounce words distinctly during inspiration as well as expiration ; and examining stutterers by the same test, I found their impediment equally affected. The tongue, the palate, the cheeks, the lips, the teeth, and their alveoli, and their different connecting media, appear to me to be the organs to look for the seat of stammer, the lungs, air-tube, thorax, and respiratory muscles, being subservient to them in speech.

In many of the cases of stutter in which I operated, indeed I may say in all, the patients were more or less relieved; but in those cases which did not remain permanently relieved, including those in which I excised the tonsils and uvulæ, I attribute the momentary benefit to the effect of an operation upon the nervous system of the individuals. And this fact should make the public guarded against exhibitions got up for the display of professional dexterity, and the profession wait 
for some months the results of such charlatanism, before sanctioning by its authority one operation or another, or indeed any operation at all. Magna est veritas, et pravalebit.

\section{ROYAL MEDICAL AND CHIRURGICAL SOCIETY. \\ Tuesday, March 28, 1841.}

Dr. WILLIAMs, President.

READ, OBSERVATIONS ON THE BLOOD DIBCS AND THEIR CONTENTS. BY JOHN QUECKETT, STUDENT OF HUMAN AND COMPARATIVE ANATOMY AT THE ROYAL COLLEGE OF SURGEONS. COMMUNICATED BY DR. PEREIRA.

T'H E author's observations in the paper whose title has first been given, lead him to the following conclusions. That each red particle of human blood is a flattened circular disc, consisting of an outer membrane or envelope, with a gelatiniform fluid in its interior, which, under certain circumstances, is capable of becoming granular, and of escaping from the envelope in the form of small globules; the general number from each disc being about six or seven; and that the discs may present either a biconvex or biconcave surface, the latter form being, by far, the most common. The author has hitherto failed in making out the existence of a central spot or nucleus as usually described. He declines stating at present what he has ascertained the contained granules to be, intending to lay before the Society, at some future period, not only this, but an important part played by them in some of the effects of inflammation.

The author describes at considerable length the appearances presented by the granules, both in the act of escaping from the discs, and afterwards pointing out the confirmation furnished by his observations, of the correctness of the description given by Lewenhoeck, of the appearances presented by the globules of the blood, that distinguished observer having described each disc as composed of six smaller ones.

REA d also, a Case OF Partial softening OF THE RIGHT CORPUS STRIATUM, AND LEFT LOBE OF THE CEREBELLUM, WITH IMPERFECT PARALYSIS OF THE LEPT ARM AND RIGHT LEG.

The patient is described as having suddenly lost all sensation and almost all power of motion in the left arm and right leg; neither the intellect nor any organs of sense having been affected before or being affected after the attack. The only preceding syınptom had been muscular weakness. She appeared to have undergone a fit, which lasted about half an hour, five months before. Between her admission into St. Thomas's Hospital, September 15, 1840, and her death, she regained the complete power of retaining her evacuations, which had been lessened, but not destroyed, by the last attack; and up to the 3rd of November, her other paralytic symptoms had diminished. On that day, 2 fit occurred and was repeated January the 6 th, 13 th, and 23rd. In a few hours after the last fit she died. The pulse had been uniformly slow and feeble; her strength had been supported, and no active treatment adopted.

Serum was found, on examination, under the arachnoid of the brain; otherwise it was healthy, except at two points, in which there was a softened portion of medullary substance, namely, in the right corpus striatum and the left lobe of the cerebellum.

The cause of death in this case, the author presumes to have existed in the softened points, which he considers as not of the nature of apoplectic clots or of ramollissement; and he considers the mode in which the lesion produced death, as different in kind from what is usually observed where organic disease, after long quiescence, becomes the cause of death. He, therefore, presumes this event was attributable to disease distinct from the parts primarily affected.

The author, in conclusion, points out discrepancies between the phenomena of this case, and the general rules laid down in regard to the relation between the affected portions of brain and the paralyzed parts of the body; and expresses his opinion, that these rules rest at present on an imperfect foundation.

\section{WESTMINSTER MEDICAL SOCIETY.}

Saturday, March 20, 1841.

Mr. streeter, President.

STAMMERING.-MR. YEARSLEY READ A PAPER ON STAMMERING, IN WHICH HE DESCRIBED AN OPERATION WHICH HE BELIEVED TO BE PECULIAR TO HIM.

Mr. Yearsley, in most cases, removed the uvula entirely, chiefly with the view of throwing both arches of the palate into one. When the tonsils were so much enlarged as to project beyond the columns of the fauces, the uvula was then partially removed, and also so much of the tonsils as projected : in only one case had anything like severe hæmorrhage taken place, and in this the bleeding. continued for four hours. The operation, however, might not be unattended with danger, when there was a diathesis to hæmorrhage present in the system.

Mr. Dowing believed that three kinds of operation had been recommended and performed for the cure of stammering; the one proposed by $\mathbf{M r}$. Yearsley, that described by Dieffenhach, and that practised by Mr. Bennett Lucas. He (Mr. Dowing) had seen cases operated upon by Mr. Yearsley and Mr. Lucas. In all these cases, as well as in those he had seen operated upon by Mr. Yearsley, the operation at the time certainly appeared successful; but he contended that we had not yet had sufficient time to determine whether the good effect would be permanent. Looking at the invariable success of all the operations, which were so remarkably different in kind, he could not help thinking that much of the effect was dependent on the shock to the nervous system by the operation and the loss of blood consequent upon it. Mr. Lucas's operation consisted in the division of the frænum linguæ, and the removal of a portion of the anterior fibres of the genio-hyo-glossi muscles : Mr. Lucas did not perform his operation indiscriminately on all who applied, as Mr. Yearsley appeared to do, but always thoroughly examined into each case, and investigated, as far as possible, into its history and causes; he only operated in such cases as were likely to be benefited by the proceeding. In the fourteen cases operated upon, the tongue was tied down either by the frænum or the muscles beneath; and in all these cases the operation had been successful. In other cases the success had appeared 